\title{
Blood Morphology in Dogs with Dirofilariasis
}

\author{
Roman Slobodyanik ${ }^{1}$, Svetlana Zykova, ${ }^{1, *}$, Larisa Belova $^{2}$, and Andrey Kryazhev ${ }^{3}$ \\ ${ }^{1}$ Perm Military Institute of National Guard Troops, Department of Cynology, Perm 614112, Russia \\ ${ }^{2}$ St. Petersburg State Academy of Veterinary Medicine, St. Petersburg 196084, Russia \\ ${ }^{3}$ Vologda State Dairy Farming Academy named after N.V. Vereshchagin, Vologda 160555, Russia
}

\begin{abstract}
The article addresses the results of a study of blood morphology parameters in healthy dogs vs. dogs diagnosed with dirofilariasis. In the group of infected animals, the most significant difference was 4.9 higher granulocytes. Another significant contribution is eosinophils and, to a lesser extent, neutrophils and monocytes. In blood of infected and healthy animals, no difference was found in terms of the count of red blood cells, haemoglobin, and haematocrit. Anisocytosis value in red blood cells is probably related to the compensated processes, and differs insignificantly between healthy and infected animal groups. Blood morphology of infected animals is characterized by mild reticulocytosis, not exceeding $20 \%$ of physiological norm. In the group of infected dogs, platelet count corresponds to the lower boundary of physiological norm. In healthy animals' group, platelets and platelet crit is physiologically normal. Leukopenia, lymphocytopenia are detected. Apparently, the reason behind the findings is age of the animals and degree of their adaptation to the progress of the invasive process.
\end{abstract}

\section{Introduction}

Canine vector-borne diseases (CVBD) are gaining an increasing importance. Causative agents and transmitters of these diseases (fleas, mosquitoes, ticks and sandflies) are ubiquitous. Notwithstanding the efforts of the practical veterinary medicine, the spread of ectoparasites is universal.

In the Russian Federation, dirofilariasis is studied by a number of science centers and research teams. The spread of dirofilariasis has long been treated as a problem of the NorthWest region of Caucasus [1]. Recently the veterinary services are registering a growth in incidence of invasion in dogs inhabiting more temperate latitudes.

Since 2000, the research has reflected a growth in the number of dogs invaded by the two dirofilariasis causative agents: Dirofilaria immitis and Dirofilaria repens. According to different sources, the spread of dirofilariasis is within 9 to $13-16.6 \%$

The problem transcends the boundaries of veterinary medicine. Since 2006, Rospotrebnadzor (Russian Federal Service for Surveillance on Consumer Rights Protection and Human Wellbeing) registers the growth of dirofilariasis incidence among the population of the Russian Federation. There are several causes to this: dirofilariasis is

\footnotetext{
* Corresponding author: zykova.sv@rambler.ru
} 
transmitted via bites of several mosquitoes: Aedes (Stegomyia), Culex, Anopheles, Coquillettidia (Mansonia) [3], out of which 70 types of mosquitoes are capable of maintaining the development of larvae of Dirofilaria immitis, and 20 types of mosquitoes can act as bridging hosts of Dirofilaria repens. In some instances, mixtinvations are registered [4-8]. Parasite fauna of the region is formed under the influence of many climatic, geographic, and socio-economic factors. To a large extent, dirofilariasis spread is facilitated by anthropogenic contributors, e.g. presence of stagnant water bodies, as well as territories with high dog populations [9].

The research conducted in Russia over the recent decades for study of parasite fauna in the population of wild vertebrates of the families of Canidae and Felidae shows high rates of invasion in carnivores with both Dirofilaria immitis (Leidy, 1856) and Dirofilaria repens (Railliet et Henry, 1911) [10;,11,12,13, 14].

Dirofilaria infection rate in wild animals inhabiting the South of Russia remains high. According to the literature, in Krasnodar Krai, out of the 60 tested jackals, Dirofilaria immitis helminths were found in $14(23,3 \%)$, Dirofilaria repens helminths in $6(10 \%)$, and mixtinvation with $D$. immitis and $D$. repens in $4(6.7 \%)$ animals. Invermination with this species is also found in raccoon dogs, badgers, foxes and leopard cats $[11,12,13,15]$.

Incidence of $D$. repens and $D$. immitis infection in foxes has been examined in various eco-geographic zones of the Central Non-Black Earth Belt of Russia: in Moscow, Ivanov, Vladimir, Kostroma, Smolensk, Ryazan and Yaroslavl Oblasts [10, 14]. The obtained data shows that in the conditions of anthropogenic systems (agricultural landscapes, territories adjacent to human settlements) wild animals participate in circulation of zoonotic helminthiases. Wild animals play the role of the main ecological link - as the source, accumulation and spread factor of dirofilariasis causative agents [16]

Dirofilariasis is one of the most dangerous invasive diseases in dogs. Invasion caused by $D$. Immitis is the most critical one.

A specific relation has been observed between service use of dogs and the risk of dirofilariasis infection. Further analysis of dirofilariasis incidence dynamics in dogs and their use over years has shown that the invasion tends to be the most extensive in homeless (unsupervised) and service dogs. No examination or treatment is performed in regard to unsupervised animals. Service dogs, on the other hand, undergo annual scheduled diagnostic testing, prevention and treatment of dirofilariasis [17]. German Shepherds, EastEuropean Shepherds, Caucasian Shepherds, Central Asian Shepherds, Doberman Pinchers, Giant Schnauzers and Boxers are breeds that are most susceptible to dirofilariasis infection $[18,19]$. The most vulnerable dog ages are 4 to 6 years old; according to some sources, high risk of infection remains until 8 years of age [9].

At the same time, in hunting and domestic animals, this invasion is usually diagnosed incidentally. Preventive treatments are performed by animal owners sporadically, since para. 9.4. of Sanitary and epidemiological regulations and norms 3.2.3215-14 specifies the need to examine and anthelminthic treatment domestic animals without listing specific drugs and frequency of their use [17].

Due to the prevailing population of German Shepherds in the security forces of the Russian Federation, the problem of dirofilariasis spread is highly relevant. Research of the invasion process dynamics has shown seasonality of the disease which grown considerably within the mosquito breed period in summer.

\section{Materials and Methods}

In case of dog infection with Dirofilaria immitis, 3 forms of the disease in terms of clinical symptoms manifestation are distinguished. The clinical stage of dirofilariasis development correlates with the number of mature helminths. The first stage is a subclinical form of the 
disease and has next to no apparent clinical symptoms. Medium severity degree of the disease manifests as a cardiopulmonary process with renal insufficiency. The most severe form is accompanied by systemic changes in the body (cardiopulmonary disease with thromboembolic complications, accompanied by renal and hepatic insufficiency) [18]. Invasion process caused by Dirofilaria repens can manifest in 3 forms: subclinical, dermal and the most severe pseudo-tumorous form of the disease [19].

We have performed diagnosis of dirofilariasis and hematological analysis in healthy and infected dogs [20].

Notably, infection with dirofilariasis is accompanied with significant decrease in physical stamina of dogs, their olfactory activity, and ability to perform service and combat tasks. Most dogs eventually die of thromboembolism and cardiovascular complications. The research involved German Shepherd and East European Shepherd breeds with a total headcount of 98 animals. The results of blood morphology study are shown in the Table below.

Table 1.Blood morphology parameters in dogs

\begin{tabular}{|c|c|c|}
\hline Parameters & Infected animals & Healthy animals \\
\hline WBC (leucocytes) & $9.10 \pm 1.41$ & $11.20 \pm 1.20$ \\
\hline LYM (lymphocytes) & $3.20 \pm 0.54$ & $7.63 \pm 0.61$ \\
\hline MON (monocytes) & $1.05 \pm 0.09$ & $0.80 \pm 0.14$ \\
\hline GRA (granulocytes) & $5.40 \pm 0.96$ & $1.70 \pm 1.06$ \\
\hline LYM\%(lymphocytes \%) & $32.6 \pm 4.06$ & $73.90 \pm 5.77$ \\
\hline MON\% (monocytes \%) & $10.75 \pm 0.74$ & $17.80 \pm 0.62$ \\
\hline GRA\% (granulocytes \%) & $56.00 \pm 4.57$ & $7.07 \pm 0.21$ \\
\hline RBC (red blood cells) & $6.95 \pm 0.34$ & $17.40 \pm 0.60$ \\
\hline HGB (haemoglobin) & $16.45 \pm 0.57$ & $44.10 \pm 1.48$ \\
\hline HCT (haematocrit) & $42.00 \pm 1.51$ & $62.90 \pm 0.67$ \\
\hline MCV (Mean Cell Volume) & $59.85 \pm 0.98$ & $23.40 \pm 0.67$ \\
\hline MCH (Mean Cell Haemoglobin) & $23.80 \pm 0.45$ & $37.00 \pm 0.30$ \\
\hline MCHC (Mean Corpuscular Haemoglobin & $39.45 \pm 0.31$ & $14.80 \pm 0.37$ \\
\hline Concentration) & & $34.30 \pm 0.80$ \\
\hline RDWCV (Red blood cell distribution width) & $14.95 \pm 0.31$ & $160.00 \pm 13.24$ \\
\hline RDWC\% (Red blood cell distribution width, & $28.20 \pm 1.22$ & $8.60 \pm 0.12$ \\
\hline \%) & & $0.13 \pm 0.01$ \\
\hline PLT (Platelets) & $141.50 \pm 21.60$ & $17.70 \pm 0.72$ \\
\hline MPV (Mean Platelets Volume) & $9.05 \pm 0.31$ & $18.10 \pm 0.98$ \\
\hline PCT (Platelets Cell) & $0.124 \pm 0.017$ & \\
\hline PDV (Platelets width) & $18.20 \pm 0.97$ & $20.05 \pm 2.77$ \\
\hline PLCR (Platelets Large Cell ratio) & & \\
\hline
\end{tabular}

The blood morphology parameters were examined using IDEXX Laser Cyte automatic analyzer.

Against the invasion background, changes in the blood morphology of dogs are accompanied by a decrease in red blood cells, minor decrease in concentration of haemoglobin, a decrease in the number of leucocytes and significant eosinophilia. Biochemical parameters of blood are characterized by hyperproteinemia, increasing activity of AST, ALT enzymes, an increase in the levels of bilirubin and urea [22, 23].

Dirofilariasis diagnosis is based on the analysis of epizootological situation, clinical manifestations, as well as the results of laboratory tests for presence of microfilaria in dog blood.

Several methods exist for diagnosis of dirofilariasis. The most common ones are the method of thick blood smear with further microscopic examination, Knott's method [24], Yastreb's method (concentration with distilled water) [25], and filtration method [26]. More 
reliable methods are ELISA test (enzyme-linked immunosorbent assay) and specific antigen-based immunodiagnosis reaction [27].

It is of special interest to look into using test systems for detection of Dirofilaria immitis in dogs, including its amicrofilaremic form, where diagnosis is presently extremely complicated. Use of test systems produced in the US and Korea, usually as an express method, significantly facilitates detection of invasion, however, only in regard to one causative agent type $-D$. immitis. In regard to the other type, $D$. repens, laboratory methods of clinical diagnosis boil down to serological tests and PCR. The capabilities of instrumental diagnosis methods, such as echocardiography, chest radiology, electrocardiography, ultrasonic test (UT) ensure reliable determination of invasion extension in dogs [28].

\section{Results and discussion}

The analysis of blood morphological parameters such as haematocrit, haemoglobin, red blood cell count, shows that there is less than $10 \%$ difference in these parameters between the groups of healthy and infected animals. We assume that compensated hemolysis causes a decrease in red blood cell count, level of haemoglobin, and red blood cells mean volume. Anisocytosis of red blood cells (RDWC) in infected and healthy animals differs between the groups and insignificantly from physiological norm, which amounts to $11.9-16 \times 10^{3} / \mathrm{L}$.

Significant differences between the groups of infected and healthy dogs are observed in terms of the level of granulocytes (in absolute values and in percent of the total ratio between granulocytes and agranulocytes). A significant contribution in the increase of granulocyte count is probably made by eosinophils, as well as neutrophils, and to lesser extent monocytes.

Blood morphology manifests with minor reticulocytosis, not exceeding $20 \%$ of physiological norm (MCHC), amounting to $32-38 \mathrm{~g} / \mathrm{L}$.

In terms of the platelet count, parameters of infected dogs are approaching the lower limit of physiological norm (PLT $\left.-190-530 \times 10^{9} / \mathrm{L}\right)$. In the group of healthy dogs, platelet count and platelet crit are physiologically normal.

It was found that monocytes (in \% and in total count) in the healthy group correspond to the physiological norm (MON 3-10\%), whereas in the infected group the result is slightly higher than the norm.

In order to control dirofilariasis incidence in service dogs, prevention measures include acaricide drugs.

Use of moxidectin-based drugs enables effective prevention. Literature describes a reaction of hepatic marker enzymes increase: alanine aminotransferase (ALT), aspartate aminotransferase (AST) [28]. Use of anthelminthic drugs is recommended to be accompanied with hepatoprotective medications preventing fatty liver disease. The cytoprotective activity mechanism lies in the unique ability of antioxidants to prevent freeradical oxidation of hepatocyte membranes. The role of hepatoprotectors is important as a means of preventive therapy in order to decrease toxic effects of antigens produced by dirofilaria [29].

The veterinary activity regulations according to Sanitary and epidemiological regulations and norms 3.2.3215-14, Section IX, stipulate the procedure for prevention of dirofilariasis. The action plan consists of extermination of mosquitoes, identification and anthelminthic treatment of invaded dogs, prevention of contact between mosquitoes, humans and animals. All actions include both veterinary and general aspects, e.g. arrangement of dog walking placed away from water bodies where mosquitoes usually breed. In dirofilariasis foci, where high invasion intensity is found in dogs, prevention 
steps include thorough treatment of water bodies (delarvation) and treatment of residential and non-residential premises with insecticides [30].

Other promising methods include extermination of mosquitoes using long-action repellents: imagocides, larvicides, as well as barrier methods for protection of humans and animals. One of the most prospective and relevant ones is permethrin, a pyrethroid manifesting high effectiveness and providing protection from many insects [31].

Dirofilariasis prevention in service dogs consists of a set of preventive measures to avoid infection: treatment of animal fur with insect- and acaricide substances, use of anthelminthic treatment and hepatoprotective drugs. Import substitution and cost saving is achieved through use of native counterparts based on fipronil and moxidectin. The cost of preventive drugs is times less than the cost of treatment of infected animals.

\section{Conclusion}

To conclude, invasion, and specifically development of dirofilariasis, causes insignificant changes in the blood morphology. It was discovered that dirofilariasis invasion is not always accompanied by high RBC count. Leukopenia, lymphocytopenia were found. The blood had high counts of granulocytes (due to eosinophils) influencing the antigen structure of dirofilaria. Apparently, the cause of changes was the age of animals and degree of the invasive process.

\section{References}

1. V. M. Kravchenko, G. S. Itin, G. A. Kravchenko, Yu. I. Shcherbakha, Epizootic situation in terms of dirofilariasis in the North-West of the Caucasus region, Publications of the Kuban State Agricultural University, 46, 171-175 (2014)

2. S. A. Nagorniy, L. A. Ermakova, M. P. Chernigov, Yu. V. Kiosova, Service dogs infected with dirofilariasis in Russia, theory and practice of parasitic diseases control: published reports of the scientific conference held at All-Russian Scriabin Scientific Research Institute for Fundamental and Applied Parasitology of Animals and Plants. M. 20, 388-393 (2019)

3. S. A. Roslavtseva, Mosquitoes and dirofilariasis. Disinfection activities, (89)3, 44-51 (2014)

4. Yu. G. Beskrovnaya, S. A. Nagorny, Mosquitoes infected with microfilariae of Dirofilaria spp. in Rostov-on-Don, Theory and practice of parasitic diseases control: published reports of the scientific conference held at All-Russian Scriabin Scientific Research Institute for Fundamental and Applied Parasitology of Animals and Plants. M. 7, 66-68 (2006)

5. A. P. Kovtun, R. S. Arakelyan, A. F. Jafarov, I. I. Oleiynik, Mosquitoes infected with Dirofilaria spp. and disease prevention in the Astrakhan region. Medical parasitology and parasitic diseases, 4, 44-45 (2008)

6. C. A. Palmer, B. M. Wittrock, D. D. Christensen, Ultrastructure of Malpighian tubules of Aedes aegypti infected with Dirofilaria immitis. J. Invert. Pathol, 48, 310-317 (1986)

7. G. Capelli, F. A. di Regalbono, G. Simonato, et al., Risk of canine and human exposure to Dirofilaria immitis infected mosquitoes in endemic areas of Italy. Para. Vect. 6(60) (2013) 
8. M. Genchi, L. Rinaldi, L. Venco, G. Cringoli, A. Vismarra, L. Kramer, Dirofilaria immitis and D. repens in dog and cat: A questionnaire study in Italy. Vet Parasitol Mar; 267, 26-31 (2019) doi: 10.1016/j.vetpar.2019.01.014.

9. I. A. Arkhipov, D. R. Arkhipova, Dirofilariasis. Moscow, Publishing house of the Russian Academy of Agricultural Sciences, 194 (2004)

10. O. N. Andreyanov, A. V. Uspensky, V. V. Gorokhov, A. V. Khrustalev, L. A. Bundina, Helminthozoonozis of trade carnivores of the central region of Russia. Publications of the scientific conference Theory and practice of parasitic diseases control, Moscow, 17, 25-26 (2016)

11. M. I. Zverzhansky, N. Yu. Basova, A. V. Tulov, Parasitocenosis of the jackal (Canis aureus L.) with the presence of the Dirofilaria immitis nematode (Leidy, 1856) in the trophic-epizootic chains of the foothill area of the Krasnodar Territory. Publications of the scientific conference Theory and practice of parasitic diseases control, Moscow, 12, 212-215 (2011)

12. G. S. Itin, Ecological and faunistic review of wild carnivorous helminths of the Krasnodar Territory. Publications of the scientific conference Theory and practice of parasitic diseases control Moscow, 11, 219-222 (2010)

13. V. M. Kravchenko, Dirofilariasis of carnivores in the North-West of the Caucasus region (epizootic situation, pathogenesis, pathomorphological characteristics). Doctoral thesis, Stavropol State Agricultural University, Stavropol, 334 (2015)

14. B. V. Yastreb, V. M. Shaitanov, O. N. Andreyanov, B. G. E. N. Abalikhin, Kryuchkova Common fox as a reservoir of dirofilaria spp. infection in wild nature of the central region of Russia. Publications of the scientific conference Theory and practice of parasitic diseases control. Moscow, 18, 562-563 (2017)

15. L. N. Shipkova, T. V. Lysykh, E. A. Malgina, Features of the course of dirofilariasis in the Krasnodar Territory and in Novy Urengoy. Publications of the scientific conference Theory and practice of parasitic diseases control. Moscow, 16, 494-497 (2015)

16. R. V. Slobodyanik, S. S. Zykova, V. V. Masaytis, Jackal (Canis aures L) as a possible carrier of dirofilariasis in the Republic of Armenia. Collected works: Hunting science and hunting economy in Russia and the former Soviet countries. Current state and prospects (Reading in memory of Silantiev A.A.) materials of the All-Russian scientific and practical conference. St. Petersburg, 95-99 (2020)

17. C. C. Evans, E. J. Burkman, M. T. Dzimianski, A. R. Moorhead, M. D. Savadelis, C. Angenendt, S. Zymny, D. Kulke, Periodicity of Dirofilaria immitis in Longterm Infections. Parasitol Res. 2017 Aug 116(1), 75-80 (2017) doi: 10.1007/s00436-0175493-z.

18. V. B. Yastreb, Helminthiasis: echinococcosis and dirofilariasis: biomorphological characteristics of pathogens, improvement of control measures. Author's abstract from doctoral thesis Moscow, 49 (2009)

19. S. Zykova, R. Slobodyanik, L. Belova, A. Kryazhev, A. Savinkov, E3S Web of Conferences. XIII International Scientific and Practical Conference "State and Prospects for the Development of Agribusiness - INTERAGROMASH 2020", 03014 (2020)

20. R. V. Slobodyanik, S. S. Zykova, Dirophilariosis monitoring in creed dogs in the Ararat region of Armenia. Collected works: State and prospects for the development of the agro-industrial complex. Jubilee collection of scientific papers of the 13th international scientific and practical conference dedicated to the 90th anniversary of the Don State Technical University (Rostov-on-Don Institute of 
Agricultural Engineering), in the framework of the 23rd Agro-Industrial Forum of the South of Russia and the Interagromash exhibition. In 2 volumes, 665-668 (2020)

21. A. A. Bittirova, S. Sh. Kabardiev, I. A. Bittirov, Sh. S. Kabardiev, S. A. Begieva, A. M. Bittirov, Biochemical composition of the blood of dogs on the background of the influence of intensive invasion of dirofilariasis. Theory and practice of parasitic diseases control: published reports of the scientific conference held at all-Russian Scriabin Scientific Research Institute for Fundamental and Applied Parasitology of Animals and Plants. 20, 132-135 (2019)

22. S. Sh. Kabardiev, The influence of intensive dirofilariasis invasion of dogs on the morphological profile of blood. Theory and practice of parasitic diseases control: published reports of the scientific conference held at All-Russian Scriabin Scientific Research Institute for Fundamental and Applied Parasitology of Animals and Plants. 20, 238-241 (2019)

23. J. I. Knott, A Method for making Microfilarial Surveys on Day Blood. Trans. Roy. Soc. Trop. Med. Hyg. 33(2), 191-196 (1939)

24. O. M. Torres-Chable, C. M. Baak-Baak, N. Cigarroa-Toledo, B. J. Blitvich, L. G. Brito-Argaez, Y. N. Alvarado-Kantun, C. V. Zaragoza-Vera, G. Arjona-Jimenez, L. G. Moreno-Perez, P. Medina-Perez, C. I. Machain-Williams, J. E. Garcia-Rejon, Molecular detection of Dirofilaria immitis in dogs and mosquitoes in Tabasco, Mexico, J Vector Borne Dis. Apr-Jun 2018, 55(2),151-158 (2018) doi: 10.4103/09729062.242563.

25. F. Dantas-Torres, D. Otranto, Dirofilariosis in the Americas: a more virulent Dirofilaria immitis? Parasit Vectors. 2013 Oct 2, 6(1), 288 (2013) doi: 10.1186/17563305-6-288.

26. O. V. Byakova, L. V. Pilip, Features of diagnostics of dirofilariasis in duty (service) dogs. Theory and practice of parasitic diseases control: published reports of the scientific conference held at all-Russian Scriabin Scientific Research Institute for Fundamental and Applied Parasitology of Animals and Plants. 19, 107-111 (2018)

27. A. M. Ionică, I. A. Matei, G. D'Amico, L. V. Bel, M. O. Dumitrache, D. Modrý, A. D. Mihalca, Dirofilaria immitis and D. repens show circadian co-periodicity in naturally co-infected dogs. Parasit Vectors. 2017 Feb 28, 10(1), 116 (2017) doi: 10.1186/s13071-017-2055-2

28. S. S. Zykova, Prevention of metabolic disorders and liver diseases in service dogs: Acute problems and prospects of service dog breeding: collection of materials of the All-Russian scientific-practical conference. Perm. 45-48 (2018)

29. Sanitary and epidemiological regulations and norms 3.2.3215-14. Prevention of parasitic diseases on the territory of the Russian Federation. Electronic version: http://docs.cntd.ru/document/420233490 (Last accessed 04/21/2020)

30. N. Mencke, Acaricidal and repellent properties of permethrin, its role in reducing transmission of vector-borne pathogens. Vetpharma. 2(24), 46-48 (2015) 